\title{
Effect of Rubric-Based Feedback on the Writing Skills of High School Graders
}

\author{
Ali Alsagheer Abdelal Hasan* \\ Curriculum and Instruction Department College of Education, King Khalid University, Saudi Arabia \\ *Correspondence to: alielsa@hotmail.com
}

Abstract: This study aimed at exploring the impact of utilizing rubric based feedback on developing the EFL writing skills of Saudi high school students. This study recruited 65 students of the second semester of high school students during the academic year 2019. The experimental group consisted of 31 students, who utilized the rubric based feedback during their writing instruction, while the control group comprised 34 students, who were taught in a traditional way in the classroom. Paired t-test revealed that there was a significant difference between mean scores of both the experimental and control group participants favoring the experimental group participants; confirming the positive impact of utilizing rubric based feedback on developing Saudi high school students' writing skills. These findings have provided evidence that the rubric based feedback has effectiveness in developing the writing skills of Saudi high school students

Keywords: rubrics; feedback; writing skills; high school

Recommended citation: Hasan, A. A. A. (2022). Effect of Rubric-Based Feedback on the Writing Skills of High School Graders. Journal of Innovation in Educational and Cultural Research, 3(1), 49-58.

\section{INTRODUCTION}

Writing is one of the principal skills of language. It plays an important part in voicing one's emotions, beliefs and attitudes. By writing, people can exchange thoughts, emotions, convince and persuade other people. Writing is always the last learned skill in the process of learning, and development of any language, compared to the three remaining skills of listening, speaking, and reading. Writing, in all languages, is regarded as the most difficult skill for students to master. There is no exception in English as a foreign language learning. Even with their mother tongue, learners frequently struggle with writing their text (Anh, 2019). Writing, as stated by Mohammad, et al. (2020), is a difficult skill for both native and nonnative speakers to master because they must consider multiple factors in their writing, such as purpose, audience, content, organization, vocabulary, spelling, punctuation, and capitalization. At the most basic level, writing is a physical act of committing words or ideas to a medium. On the other hand, writing is the mental work of inventing ideas, thinking about how to express them, and organizing them into statements and paragraphs that are clear to the reader." Harmer (2007) stressed that both the content and the form are important aspects of writing a composition. Writing requires appropriate language use, text construction, layout, style and effectiveness. Harmer adds that the writing skill is a process to be followed in different phases, including the drafting stage, the editing stage, the planning stage and the final draft.

Writing is a difficult skill for L2 learners to master (Richard \& Willy, 2002). The difficulty arises from the fact that the skill of being able to generate and organize ideas and then translate them into readable text is a time-consuming and difficult skill even for native speakers. The complex skills used in writing, according to Require L2 learners not only to concentrate on planning and organizing skills at a higher level, but also on lower level spelling, punctuation, word choice skills. This is especially a problem for those who lack proficiency in the language. Writing as an important skill that students need to master with an awareness of sentence structure, correct word choice, attention to spelling and punctuation. Learners must be skilled at integrating both their linguistic knowledge and the ability to coherently and cohesively present information in their written texts. In regard to this point, some EFL learners do not achieve a very high level of proficiency in writing paragraphs or essays.

Similarly, writing is a skill that many teachers find difficult to teach, which makes it a skill that many learners do not enjoy. Success in a written task does not proceed solely from learning the language grammar and lexicon. Learning how to write in a target language is more than just learning a set of linguistic tools, but rather is also an interactive social and cultural experience. As a result, there has been an increase in the use of new techniques aimed at improving EFL learners' writing abilities (Rao, 2007; Reilly \& Reilly, 2005). This trend 
of utilizing new techniques in teaching writing has sparked a renewed interest on the part of researchers and practitioners to study the effects of providing effective and constructive feedback on developing the writing skills of EFL learners (Bitchener \& Ferris, 2012).

Therefore, the roles of teachers are needed in order to ensure students' knowledge advancement and determine whether their comprehension is satisfactory, or which part of their work they should review, or even where they have gone wrong. Jones (2005) points that teachers should provide suggestions to students during the writing process, but should not determine how each student should write. In addition, teachers should act as feedback providers who clearly articulate to their students the appropriate level of knowledge and understanding. Feedback should be recognition of what they have done well, complemented with the guidance and assistance they need to develop areas of their work that need improvement. In addition, one way to support students in their learning is to provide them with a variety of assessment activities that will stimulate their learning process.

One way to support students in their learning is by providing them with appropriate forms of assessment that will encourage students to develop their different learning processes. Assessment is vital to classroom success for both learners and teachers. It has received the attention of many contemporary teachers and educational theorists. Assessment, when directed in an effective manner can lead to enhanced student performance and motivation. assessment is most beneficial if it prompts learners to reflect on their performance or improves their skills. In turn, they should use this information in their own writing as a basis for improvement, i.e. they should avoid making the same mistakes in the future; otherwise, assessment would be of no use. The assessment should not be an end-product, but rather an ongoing process in which students can continue to use the assessment to make progress in their learning. In order to maximize a student's learning in writing, teachers should implement the "Assessment for Learning" technique in which feedback is provided to help students learn in writing.

The Assessment for learning technique informs learners of the progress they have made and empowers them to take the necessary action to improve their performance. Jones (2005) explains that "Assessment for Learning" technique is necessary in a way to promote the weaker learners to successfully reach their maximum potential while also challenging the more advanced ones. Rubric based assessment, which is suggested by the researcher to be utilized in this study, is one type of the Assessment for learning techniques.

Although there is a great deal of research on the impact of effective assessment techniques on the production of language skills in foreign literature, there is a very small number of studies in Saudi context on the relationship between the growth of foreign language writing skills and the use of assessment for learning techniques. On the other hand, the number and scope of studies that focus on utilizing assessment in teaching English as a foreign language concentrate on the relationship between "assessment of learning" instead of "assessment for learning". Thus, the purpose of this study is to investigate the effect of utilizing the rubric based feedback in teaching writing to Saudi high school graders. Besides, it is expected that the results of this study will be useful in filling a major gap in the literature and in providing guidance to decision-makers, curriculum planners and developers, instructors, and all foreign language education stakeholders to enhance the standard of the writing skill.

Lack of motivation and development among EFL writers is correlated with the assessment method used by teachers. Through the researcher visits to the English language classrooms at secondary schools, some of the assessment methods are not successful at all. In addition, students are not motivated to write because their instructors do not provide appropriate feedback. Instructors provide feedback to the students, focusing on the form and delivery of the content. Therefore, poor written performance of secondary school students is a result of the correction method and the lack of appropriate and convincing feedback provided to the student. When students write an essay and it is corrected by the teacher, they do not know the weaknesses of their writing and do not know what the teacher wants from them. The students would then feel discouraged and lose their motivation, ultimately resulting in low levels of writing performance. Based on the above, the problem of this research is crystallized in the weakness or lack of appropriate feedback provided by the teacher to students while teaching writing activities, which leads to students' weakness in writing skills.

The purpose of this study was to investigate the effects of the use of rubric based feedback in teaching writing on the development of English writing skills of Saudi high school students. In line with this key objective, the study main question is as follows: Is there a significant difference in the English writing test scores of the experimental group subjects who utilized the rubric based feedback and the control group subjects who utilized the traditional EFL classroom assessment method in teaching the writing skill?

\section{Review of Literature}

At the heart of educational discussions lies the issue of writing instruction, being a major aspect of literacy. Adler-Kassner \& O'neill (2010) state that good writing in academia is an indicator of the students' ability to interact, critically understand and show their transferred information in various disciplines. In almost every 
discipline, writing even outside scholarly circles is cardinal. The importance of the role of writing seems to be convincing in order to provide the best insight into writing skills and to make subsequent pedagogical and curricula-specific decisions in the sense of language learning. The importance of the role of writing becomes apparent. In this sense, the evaluation of English as a foreign language (EFL) was one of the hot topics of language teaching, and heavy research was carried out on its different theoretical and practical aspects (Drid, 2018).

Teaching and assessing writing in EFL context has attracted high interest among recent researchers in countries where English is taught as a foreign language. Much research has revealed the impact of utilizing rubrics in teaching and assessing writing in the EFL context. Using rubrics as a way of teaching and assessing students writing skill is more popular than ever in education nowadays. Finson (1998) states that rubrics as a guide to follow when grading students' activities. According to Finson (1998), rubrics are either holistic or analytic. Holistic rubrics are more product-oriented than process-oriented, while analytic rubrics are more process-oriented than product oriented. Rubrics show what is expected in writing assignments and describe levels of students' writing performance quality (Saddler \& Andrade, 2004).

Thus, rubrics are useful in the context of formative evaluation because they provide contextual performance information that can be used to provide input (Tierney \& Simon, 2004; Penny \& Murphy, 2009), educate students about their progress, and help in the learning process, all of which contribute to the creation of self-regulated learning (Panadero \& Jonsson, 2013; Panadero \& Alonso-Tapia 2014). Rubrics have two primary components, according to a descriptive definition: performance criteria and definitions or ratings. The former refers to the task's components, while the latter refers to the qualitative levels at which student performance can be evaluated (Penny \& Murphy, 2009).

Some studies have been conducted to determine the effectiveness of rubrics in assessing EFL/ESL students' writing ability, but only a few (Cothran, 2003; Fuchs \& Fuchs, 1986; Marzano, 2000) have demonstrated the efficacy of instructional rubrics in teaching and learning writing ability. Marzano (2000), for example, reported that rubrics, in addition to being an accurate measure of students' writing skill development, may actually promote student learning. Another study conducted by Cothran (2003) demonstrated that rubrics are a beneficial addition to teachers' instructional methods because they provide a meaningful way to plan for and interpret students' learning. Fuchs and Fuchs (1986) conducted a meta-analysis of 21 studies and concluded that teachers who use rubrics to guide instruction and assessment are more effective at increasing students' achievement than teachers who use traditional assessment methods.

Some other studies (Campbell, 2005; Rezaei \& Lovorn, 2010) conclude that rubrics are used to assess students' writing performance, while other studies (Charney, 1984; Saddler \& Andrade, 2004) revealed that rubrics are used to find out how analytical feedback provided through them helps improve instruction and the learning of writing skills. Andrade (2005) states that rubrics are used for both educational and assessment purposes. Thus, rubrics aim to provide informative feedback to students about their writing assignments and also to assess their work in more detail. According to Andrade (2000), there are different formats of instructional rubrics, but all of them have common criteria: (1) list of criteria and (2) degrees of quality.

Turgut \& Kayaolu (2015) investigated the impact of using rubrics as a teaching tool on students' writing performance in English as a foreign language. The main aim was to free students from the limited view of writing that is prevalent in EFL writing which is focused solely on the concept of proper grammar. The treatment group in their study was given a rubric that laid out a simple set of standards for good writing. They were taught how to use the rubric while writing two separate essays, while the control group wrote the same types of essays but were not taught how to use the rubric. The knowledge was gathered through student interviews and essays, which were judged using the same rubric by three independent raters. Students who got the rubric outperformed students in the control group, according to the findings. The review of the student interviews showed that, despite being initially difficult, integrating the rubrics into the course helped students understand the characteristics of good writing and then use effective techniques to achieve them in their own writing.

Mahmoudi and Buğra (2020) investigated how using rubrics along with face-to-face feedback from teachers affects students' writing performance. Grading Rubric was used in the teaching of writing skills to preparatory school students to help them understand the learning objectives and quality standards for writing skills in order to improve their writing performance. In addition, face-to-face feedback was given to students' writing assignments in order to raise their awareness of their writing flaws. The qualitative analysis of the findings based on the open-ended questionnaire and focused group interview revealed that using rubrics in teaching writing skills, as well as providing face-to-face feedback, improved students' writing performance. Students reported that after learning about the rubric, they were able to check their writing work, provide feedback on their peers' work, produce high-quality writings, and receive higher grades. 


\section{THEORETICAL FRAMEWORK}

\section{Teaching EFL writing in Saudi context}

Regardless of the importance of other English language skills, writing appears to be one of the most important to acquire. Concerning the significance of writing, perspectives on learning and teaching this skill must be focused and addressed in a variety of pedagogical practices. These practices must be applied with extreme caution in an EFL context, as the degree of writing complexity is greater than in a context where English is a first language. Writing is regarded as a difficult skill to learn and teach in Saudi Arabia and other Arab countries as EFL contexts. Thus, due to the complexity of the nature of writing, learners encounter difficulties when attempting to acquire such a skill. These complexities inherent in writing and learning to write complicate teachers' roles and contribute to the difficulty of teaching writing. When compared to a situation where English is the first language, these complexities become magnified in an EFL context.

Through his visits to Saudi schools- as preservice English teachers' monitor-, the researcher observed that high school students face a variety of challenges in writing. Students, with the exception of a very small number, are perceived to be incapable of writing an excellent piece of writing. This weakness is caused by a variety of factors. The current state of English writing teaching in Saudi context is believed to be one of the factors affecting students' poor writing performance.

Teaching writing in an EFL context is viewed as a difficult task. As a result, ineffective teaching may occur in this situation. This inefficiency is attributed to a variety of factors. In Saudi context, writing instruction is actually teacher-centered. Teachers place a premium on students' products over alternative process based approaches. Another difficulty with teaching writing in Saudi context is that authenticity appears to be lacking. Learners are instructed to write pieces for examination purposes. They learn to write solely for the purpose of passing the examination and earning points. The processes of teaching and learning are incompatible with the needs of learners in their real lives. Another important factor that affects the efficiency of students' writing is the type of feedback teachers provide their students when they deal with the writing activities.

To teach writing in the English language classroom, constructive feedback is the teachers' primary tool. Feedback is a critical component of the process-oriented approach to writing. The purpose of feedback is to incorporate it into students' writing as a part of the writing development process. Giving feedback can also be considered a skill, as it requires careful consideration of several factors when responding to students' writing. The reason for this is that students' comprehension and reception of feedback, as well as their attitude toward feedback, have a greater impact on the writing instruction process. On the other hand, the essence of providing feedback is another significant problem for teachers, as feedback must be precise, appropriate, and explicatory, as well as straightforward enough for students to understand (Wen, 2013).

However, many teachers, unfortunately, fail to adhere to the best requirements when providing feedback on their students' writing. While it should be detailed, they often end up highlighting the student's errors, putting them in red circles. Sometimes, the error portions are underlined randomly with a very broad and vague comments such as "wrong", "be careful", "punctuation"...etc. These types of feedback are of no use to students because they fail to instruct students on how to correct their writing errors. These factors contribute to a mismatch between what a teacher provides and what students desire (Wen, 2013).

\section{Rubric based Feedback}

Rubrics are used to assess students' work and grant grades based on their ability to achieve standards across a spectrum of performance benchmarks. While most teachers regard rubrics as an effective method for setting standards and awarding grades based on a student's ability to achieve certain expectations, rubrics are often underutilized as an instructional tool in the EFL classroom. Students must learn from their work. They need to make use of both their successes and their failures. Students should strive to improve with each task they complete and should be aware of the objectives they are pursuing. Teachers assist students in gaining knowledge from their work by providing constructive feedback. Much research has confirmed that feedback is among the most powerful tools teachers can use to help students work towards, reach, and ultimately exceed expectations in any given task (Finson, 1998; Panadero \& Jonsson, 2013; Penny \& Murphy, 2009; Tierney \& Simon, 2004).

Rubric based feedback is proved to be one of the most effective types of feedback utilized in teaching EFL writing activities. When an EFL teacher uses a rubric to evaluate his/her student writing, s/he will not only be held accountable for remaining objective, but s/he will also be able to clearly communicate expectations to students. By utilizing rubric based feedback in the EFL writing classroom, students are evaluated objectively in light of their response to the objectives of the writing task and craft their work according to the expectations of the rubric. 


\section{What is a rubric?}

A rubric is an indicator of what students need to do well on their work, whether it's written, oral or visual. It can be used to mark participation in class, student grades and overall standings. Rubrics are different from traditional methods of assessment in that they provide clear evidence of student progress throughout the learning process (Rezaei and Lovorn, 2010). Rubrics answer the age-old student question of "Why did you give it this grade?" by setting forth specific criteria, defining specific requirements for meeting those criteria, and assigning numerical scores to each level of performance. "Instructional rubrics help teachers teach as well as evaluate student work. At their very best, rubrics are also teaching tools that support student learning" (Andrade, 2003).

The rubric criteria developed to judge the quality of student work are important for effective performance assessments because they clearly communicate what is valued, and what is required, in the work. These criteria for quality will help students to learn what it takes to be successful. When students and teachers share the same vision and set of goals, they develop a common vocabulary to discuss and communicate about it. We are all working towards the same common goal. This helps to improve student achievement (Wiggins,1998). Thus, Students can improve their performance in class if they better understand what standards they should meet.

Arter \& McTighe (2000) state that rubrics can be utilized by all content areas and grade levels. The language used to describe the criteria used should be appropriate to the students' level. For example, icons or graphics can be used to help younger learners develop understanding of students' performance level. Again, an elementary school teacher may grade students by using smiley faces to represent the students' achievements.

Whittaker, et al. (2001) define the advantages of rubrics to students as follows: They see specific criteria needed for success in a particular project, assignment, or test; They are able to develop their meta-cognitive skills by monitoring their own progress on assignments and tasks; Students are encouraged to prepare themselves for success in college, students should become knowledgeable about the standards required to succeed in college; and They can use the rubric as a final review/check before their assignments submission.

\section{Types of rubrics}

Effective rubrics are effective because they meet the needs of a both teachers and learners as well and accomplish a specific learning objective. Rubrics can be holistic or analytic; general or task-specific; and used for formative or summative assessment. The following is a brief explanation of these types: (a) Holistic rubrics are used to classify several related criteria into categories for grading or scoring. They require teachers to focus on one level or rating of performance that best exemplifies the overall quality of performance or product. They are most often used to provide an overview of student work (Whittaker, et al., 2001); (b) Analytic rubrics provide a more detailed assessment than a single, broad rubric. The assessment rubric consists of numeric or letter grade values for the top and bottom axis, as well as a scale from Exceptional to Poor (or Professional to Amateur, and so on). Side axis includes a detailed assessment of each critical component. Analytic rubrics can provide more weight to different factors; (c) General rubrics include broad measures of performance. This type of rubric allows for the same rubric to be used for multiple tasks, but lacks specifity; (d) Task-specific rubrics are very specific to a specific task and constitute a reliable assessment of performance on a specific task. The drawback of task-specific rubrics is that they are time-consuming to develop, requiring a great deal of time and effort to document (Schreyer Institute for Teaching Excellence, 2004); and (e) Rubrics, both formative and summative can be used in classroom assessments. A rubric that clearly defines a teacher's expectations promotes students to monitor their progress toward the learning standards as they work on a given project. When rubrics are used to inform instruction, they serve as a form of formative assessment. The rubrics can also be used as a form of summative assessment to assign grades for a project or assignment (Jackson \& Larkin 2002).

\section{How to make effective rubrics}

Stevens \& Levi (2013), Huba \& Freed (2000) Rhodes (2009) see the following are requirements for making effective rubrics: 1) Transparency is required. Students are required to have a copy of the rubric before the performance task. These are not an unexpected cut off. Please hand back the rubric with the assignment; 2) Rubrics are attached to Assignments. Require all students to attach a rubric to their work when delivering their work. Some instructors seek feedback from their students prior to handing in the work for grading; 3 ) Leverage rubrics to manage your time. As you mark the assignment, you should circle, highlight or otherwise designate the level of performance achieved for each criterion. Here you will save a great deal of time as questions will not be required. Include any additional specific or overall comments that do not fit within the rubric's criteria; 4) Rubrics should be revised occasionally. Determine the final grade of the assignment based on the grading rubric. If the work meets the criteria but appears to have exceeded or not met the overall quality you are seeking, revise the rubric for the next time you teach the course. If work performs well in some areas 
but not in other areas, you should decide beforehand how the grade will be calculated. Some scoring rubrics will provide varying weights to various questions, be sure to specify that in the rubric.

\section{METHODOLOGY}

\section{Study Design}

This This study used a pre-test-post-test quasi-experimental control group design. The members of the control group received the usual method of teaching writing in the classroom, while the members of the experimental group used the rubric based feedback. In experimental studies, researchers' main aim is to demonstrate the impact of independent variables on dependent variables in experimental research designs by monitoring external variables that are likely to affect the study process and outcomes. The significant differences in teaching performance and skills between the control and experimental groups were determined in order to evaluate the impact of utilizing learning rubric based feedback on the writing skill.

\section{Participants and Context}

This study recruited two intact classes consisting of 65 Saudi secondary school students during the first semester of 2019. The experimental group consisted of 31 students who utilized rubric based feedback in their writing activities while the control group consisted of 34 students who utilized traditional teaching methodology.

\section{Instrumentation}

A writing test was devised to assess the writing performance of the study sample. The test consisted of three questions: question one dealt with a controlled writing activity in which students were asked to write a paragraph by answering a list of questions; question two dealt with a guided writing activity where student were given a picture and asked to write a paragraph, question three dealt with a free writing activity where students were asked to write a paragraph about a certain topic. A three - level rubric was devised by the researcher which served as a checklist in marking the writing test. The rubric was scaled from excellent to poor. Both the test and the rubric were face validated by some jury members who are experienced in the field of TEFL and measurement and evaluation. Piloting was carried out to determine the reliability of the instrument. KuderRichardson 20 (K-R20) was used to determine the internal consistency of the instrument. The reliability coefficient of the test was 0.88 , indicating satisfactory level of reliability.

\section{Prior to Experimentation}

Before performing the research, a writing test was administered to subjects to eliminate any possible differences between the experimental and control groups. When data from the pretesting were analyzed using the t-test, no significant differences were found between the subjects of the control and experimental groups on the pretesting of their writing (Table 1). Since the two groups had the same results on the pretest, the two groups were assumed to be equivalent.

Table 1. Results of the $t$ test of the means of the writing test of both the control and experimental groups on the pretest.

\begin{tabular}{llllll}
\hline Group & $\mathrm{N}$ & Mean & SD & t. value & Sig. \\
\hline $\begin{array}{l}\text { Control } \\
\begin{array}{l}\text { Pretest } \\
\text { Experimental }\end{array}\end{array}$ & 34 & 28.45 & 4.67 & & \\
\hline
\end{tabular}

\section{Experimentation and Data Collection}

Experimentation began at the second semester of the academic year, 2019. After experimentation, which lasted seven weeks, data were collected through the writing test which was provided as a post-test to both the experimental and control group subjects, and then analyzed using SPSS. During the experimentation period, the subjects of the experimental group were taught utilizing the rubric-based feedback during their writing practices. The subjects of the control group practiced writing activities in the traditional way. The subjects of both the experimental and the control group were exposed to the validated writing test of the study. T-Test was used to calculate the differences between the subjects of both groups in terms of the writing skills.

\section{Data Analysis}

This study has shown the positive impact of using the rubric based feedback on the writing skill of Saudi high school students. The study has also compared the scores obtained from the control and the experimental groups. The significant differences in the post test scores of the experimental and the control groups in the writing test were calculated through t-test (Table 2). 
Table 2. Paired Samples T-Test of the comparison between both the control and experimental groups on the posttest.

\begin{tabular}{lccccc}
\hline Group & $\mathrm{N}$ & Mean & SD & t. value & Sig. \\
\hline $\begin{array}{l}\text { Control } \\
\text { Posttest }\end{array}$ & 34 & 30.90 & 5.83 & & \\
Experimental & 31 & 39.41 & 4.70 & 6.44 & .0001 \\
\hline
\end{tabular}

The results showed that there was a statistically significant difference between the scores of Saudi high school students of the control and the experimental groups with respect to their writing skills, favoring the students of the experimental group. The mean scores calculated for the control and the experimental groups were (30.90) and (39.41) respectively. T value was 6.44. Thus the results showed lower than the p.value 0.05 of the significance. These results indicated that the subjects of the experimental group performed much better in the writing comprehension test in comparison with those of the control group.

\section{RESULT AND DISCUSSION}

The results of the current study revealed that there was a statistically significant difference between the mean scores of the control and the experimental groups considering the writing test. Results of this study were in favor the experimental group. Use of the t-test indicated that there were significant differences in the posttest scores of the control and the experimental groups through the writing test. Statistically significant differences were observed between the control and the experimental groups with respect to the writing performance.

The study results have shown that the subjects of the control group had a positive impact on the development of their writing skill when they were taught via traditional methods (means were 28.45 and 30.90 in the pre and post testing respectively) However, the use of rubric based feedback in writing practice had a much greater impact on the development of the writing skills in the subjects of the experimental group since rubric based feedback offered an effective, guiding, and criteria based learning environment. The findings of the current study are in line with several of the previous studies that particularly discussed the positive impact of rubric based feedback in English writing development (Campbell, 2005; Charney, 1984; Rezaei \& Lovorn, 2010; Saddler \& Andrade, 2004; Turgut \& Kayaolu 2015; Mahmoudi \& Buğra, 2020). The researcher attributed the much greater development of teaching performance skills in the subjects of the experimental group to the rubric based assessment, which is likely to provide specific and clear directions for the learners to follow. Besides, rubric based assessment proved to provide "more informative feedback" than other forms of assessment about both student strengths and areas in need of improvement.

As Piedra et al. (2010) assert, the rubric enabled feedback. It was systematic, and explicit; and clear information created new opportunities, as students were able to improve their work each week. Its design incorporated several characteristics of positive feedback identified in Sancho-Vinuesa and Escudero's research (2012). It was transparent and unambiguous for students, as previous research indicated (Gikandi et al., 2011). As a result, it has encouraged students to take an active role in assessment, encouraging self-reflection and ownership of their own learning (Cukusic, et al. 2014). Rubric based feedback is studied with respect to its effectiveness in the field of education in Saudi Arabia in order to investigate its impact on developing the secondary school students' writing skills. To address the rarity of studies found in the literature, this study highlighted the effectiveness of utilizing the rubric based instruction in teaching EFL writing. The rubrics utilized in teaching writing to the secondary stage students emphasize metacognitive knowledge that improves students ' understanding and help them become aware of the learning process as well as their shortcomings and strengths, since it is a learner-based approach. In light of the findings of the study, rubric based instruction play a vital role in developing learner autonomy, as they encourage learners to be self-independent.

The results of the study also indicated that rubric based instruction aided in the development of students' writing abilities. Students reported that by becoming aware of writing rubrics, they were able to provide feedback on their peers' writing performances, assess their own writing performances, produce high-quality writing tasks, earn higher grades, identify their writing strengths and weaknesses, and ultimately write better. The current study corroborated previous research (Cothran, 2003; Marzano, 2000) that demonstrated that teaching rubrics in writing is extremely beneficial and constructive for students' writing performance development. According to Lund \& Kirk (2002), rubrics can guide both teachers and students through the learning and assessment process, ensuring that both parties understand what students must do to demonstrate mastery of the content.

Some studies revealed the role rubric based instruction plays in reducing anxiety in learning English as a foreign language in general and in teaching writing in particular (Al-Sawalha \& Foo 2012; Bayat, 2014). Several studies have demonstrated a negative relationship between language anxiety and performance in a language 
class (Chen \& Chang, 2004; Elkhafaifi, 2005; Sellers, 2000; Wilson, 2006). It is admitted that anxiety in EFL learning in general and writing activities in particular is related to classroom based language learning and not to language learning that occurs in a low anxiety settings. Rubric based instruction provided secondary school students experimented in this study with language settings that helped in lowering their affective filter.

\section{CONCLUSION}

The modest level of the writing skill among Saudi secondary school students was the driving force behind this research, which tried to find a solution to this problem through the use of rubric based instruction. In a similar context, this study aimed at investigating the effect of utilizing rubric based instruction on the development of the writing skills of Saudi secondary school students. The findings showed that the use of rubrics in teaching writing had a substantial positive effect on the writing skill of the secondary school students. Therefore, there is an urgent need to train in service and pre service teachers of English on how to make use of rubrics in teaching English as a foreign language. In light of the results of this study, some pedagogical implications of using rubrics are presented. To begin, teachers must locate or create appropriate writing rubrics for their students. To accomplish this, they may involve students in the preparation of the rubrics, ensuring that they are used effectively. As this study only investigates the relationship between secondary school students' English language writing performance and the use of rubric based instruction, future researchers are encouraged to study further the cause and effect of the two variables. A qualitative study is also needed to gain a deeper understanding of this issue. Future studies may investigate further factors affecting the two variables and how the use of writing assessment rubrics increases students' second language writing skills. Therefore, both universities and educational directorates are recommended to incorporate utilizing rubric based instruction into teacher education and training programs. Moreover, Students ought to be made conscious of the value of their own learning autonomy. Moreover, Future research is planned to perform similar studies to explore the efficacy of rubric based instruction in learning other skills (listening, speaking, and reading).

\section{ACKNOWLEDGEMENTS}

The author extends his appreciation to the Deanship of Scientific Research at King Khalid University, Abha, KSA for funding this work through the research groups program under grant number [R.G.P.1/286/1440]. Further, this research holds no conflict of interest and is not funded through any source.

\section{REFERENCES}

Adler, L. \& Kassner, Peggy O'Neill. (2010). Reframing writing assessment : to improve teaching and learning. Logan, Utah : Utah State University Press.

Allen, D., \& Tanner, K. (2006). Rubrics: tools for making learning goals and evaluation criteria explicit for both teachers and learners. CBE life sciences education, 5(3), 197-203.

Al-Sawalha, Salem, M. A., Chow. F., \& Foo, V. T. (2012). The effects of writing apprehension in English on the writing process of Jordanian EFL students at Yarmouk University. International Interdisciplinary Journal of Education, 1(1), 6-14

Andrade, H. G. (2005). Teaching with rubrics: The good, the bad, and the ugly. College Teaching, 53(1), 2730.

Andrade, H. L. (2006). The trouble with a narrow view of rubrics. The English Journal, 95(6), 9.

Andrade, H.G. (2003). Rubrics and self-assessment project. Retrieved from http://www.pz.Harvard.edu/ Research/ RubricSelf.htm.

Anh, Dang Thi Ngoc. (2019). EFL Student's Writing Skills: Challenges and Remedies. Journal of Research \& Method in Education, 9 (6), 74 - 84.

Arter, J., \& McTighe, J. (2000). Scoring rubrics in the classroom: Using performance criteria for assessing and improving student performance. Thousand Oaks, CA: Corwin Press, Inc.

Bayat, N. (2014). The effect of the process writing approach on writing success and anxiety. Educational Sciences: Theory \& Practice, 14(3), 1133-1141.

Bitchener, J., \& Ferris, D. R. (2012). Written corrective feedback in second language acquisition and writing. New York and London: Routledge.

Bram, B. (2018). Self and peer revisions in students' narrative paragraph writing. The Asian EFL Journal, 20(8), 232-237.

Campbell, A. (2005). Application of ICT and rubrics to the assessment process where professional judgement is involved: the features of an e-marking tool. Assessment \& Evaluation in Higher Education, 
30(5), 529-537.

Charney, D. (1984). The validity of using holistic scoring to evaluate writing: A critical overview. Research in Teaching of English, 18(1), 65-81.

Chen, T., \& Chang, G.(2004). The relationship between foreign language anxiety and learning difficulties. Foreign Language Annals, 37(2), 279- 289.

Cothran, D. J. (2003). Students' use of and perspectives on rubrics. Paper presented in a conference, Aukland, New Zealand.

Cukusic, M., Garaca, Z., \& Jadric, M. (2014). Online self-assessment and students' success in higher education institutions. Computers \& Education, 72, 100-109.

Drid, T. (2018). The Fundamentals of Assessing EFL Writing. An article. Retrieved Feb., 2012 at https://www.researchgate.net/publication/329830739_The_Fundamentals_of_Assessing_EFL_Writing/ link/5c1cc43092851c22a33codae/download.

Educational Research Service (2004). Developing and Using Instructional Rubrics.

Elkhafaifi, H. (2005). Listening comprehension and anxiety in the Arabic language classroom. Modern Language Journal, 89(2), 206-220.

Finson, K. D. (1998). Rubrics and their use in inclusive science. Intervention in School and Clinic, 34(2), 79-88.

Fuchs, L. S., \& Fuchs, D. (1986). Effects of systematic formative evaluation: A meta-analysis. Exceptional Children, 53 (3) 199-206.

Gikandi, J.W., Morrow, D., \& Davis, N.E. (2011). Online formative assessment in higher education: A review of the literature. Computers \& Education, 57, 2333-2351.

Harmer, Jeremy. (2007). How to Teach English. Harlow: Pearson Education Limited.

Jackson, C.W., \& Larkin, M.J. (2002). RUBRIC: Teaching students to use grading rubrics. Teaching Exceptional Children 35 (1), 40-45.

Johansson, J. \& Nilsson, M. (2017). Feedback as Formative Assessment on EFL Student' Writing. http://hdl.handle.net/2043/22547.

Jones, C.A. (2005). Assessment for Learning. London: Learning and Skills Development Agency.

Lund, J. L., \& Kirk, M. F. (2002). Performance-based assessment for middle and high school physical education. Champaign, IL: Human Kinetics.

Mahmoudi, F. \& Buğra, C. (2020). The effects of using rubrics and face to face feedback in teaching writing skill in higher education. International Online Journal of Education and Teaching (IOJET), 7(1). 150-158.

Marzano, R. J. (2000). Introduction to the special section. Implementing standards in schools. Updating the standards movement. National Association of Secondary School Principals 84(2).

Mohammad, A. Al-Mofti, K. Hussein, J. (2020). Difficulties of Writing in English Encountered by Iraqi EFL Learners at University Level. Journal of Critical Reviews, 7(15), 5157-51-63.

Panadero, E. \& Alonso-Tapia, J. (2014). How do students self-regulate? Review of Zimmerman's cyclical model of self-regulated learning. Anales de Psicología/Annals of Psychology, 30(2), 450-462.

Panadero, E. \& Jonsson, A. (2013). The use of scoring rubrics for formative assessment purposes revisited: A review. Educational Research Review, 9, 129-144.

Penny, L. \& Murphy, E. (2009). Rubrics for designing and evaluating online asynchronous discussions. British Journal of Educational Technology, 40(5), 804-820.

Piedra, N., Chicaiza, López, J., Romero, A., \& Tovar, E. (2010). Measuring collaboration and creativity skills through rubrics - experience from UTPL collaborative social networks course. In Paper presented at IEEE EDUCON education Engineering 2010 - The future of global learning engineering education.

Rao, Z. (2007). Training in brainstorming and developing writing skills. ELT Journal, 61(2), 100-106.

Reilly, J. \& Reilly, V. (2005). Writing with Children. Oxford: Oxford University Press.

Rezaei, A. R. \& Lovorn, M. (2010). Reliablity and validity of rubrics for assessment through writing. Assessing Writing, 15, 18-39.

Richard, J. C., \& Willy, A. R. 2002. Methodology in Language Teaching: An Anthology of Current Practice. Cambridge University.

Rhodes, T. (2009). Assessing outcomes and improving achievement: Tips and tools for using the rubrics. Washington, DC: Association of American Colleges and Universities.

Saddler, B., Andrade, H. G. (2004). The writing rubric. Educational Leadership, 62(2), 48-52.

Sancho-Vinuesa, T. \& Escudero, N. (2012). ¿Por qué una propuesta de evaluación formativa con feedback 
automático en una asignatura de matemáticas en línea? Revista de Universidad y Sociedad del Conocimiento (RUSC), 9(2), 59-79.

Schreyer Institute for Teaching Excellence. (2004). The basics about rubrics. Retrieved from http:/l www.inov8.psu.edu/toolbox/RubricBasics.pdf

Sellers, V. (2000). Anxiety and reading comprehension in a Spanish as a foreign language class. Foreign Language Annals, 33(5), 512520.

Stevens, D. \& Levi, A. (2013). Introduction to rubrics: An assessment tool to save grading time, convey effective feedback, and promote student learning (2nd ed.). Virginia: Sylus.

Tierney, R. \& Simon, M. (2004). What's still wrong with rubrics: focusing on the consistency of performance criteria across scale levels. Practical Assessment, Research \& Evaluation, 9(2), 1-10.

Turgut, F., \& Kayaoğlu, M. N. (2015). Using rubrics as an instructional tool in EFL writing courses. Journal of Language and Linguistic Studies, 11(1), 47-58.

Wen, Y. (2013). Teacher written feedback on L2 student writings. Journal of Language Teaching and Research, 427-431.

Whittaker, C.R., Salend, S.J., \& Duhaney, D. (2001). Creating instructional rubrics for inclusive classrooms. Teaching Exceptional Children (November/December 2001), 8-13.

Wiggins, G. (1998). Educative assessment: Designing assessments to inform and improve student performance. San Francisco: John Wiley \& Sons, Inc.

Wilson, J. T. S. (2006). Anxiety in learning English as a foreign language: Its associations with students variables, with overall proficiency, and with performance in an oral test. Unpublished Doctoral Dissertation. Spain: University of Granada.

Zhao, A., Guo, Y., \& Dynia, J. (2013). Foreign language reading anxiety: Chinese as a foreign language in the United States. The Modern Language Journal, 97(3), 764-778. 